\title{
EFFICACY OF ENZYMATIC DEBRIDEMENT OVER ELDERLY PATIENTS
}

Martinez-Mendez JR PhD, Ojeda-Regidor A MD, Rubio M PhD, Gonzalez-Miranda A PhD, Casado C PhD, Pereira B MD

La Paz University Hospital - Madrid (Spain)

\section{INTRODUCTION}

Bromelain based enzymatic debridement is an accurate and fast modality to debride buns but there is little publications about its indication in patients older than 65 years old. The aim of the study was evaluate the efficacy of the debridement in older patients and compare its results to an historical cohort of patients treated with the standard of care.
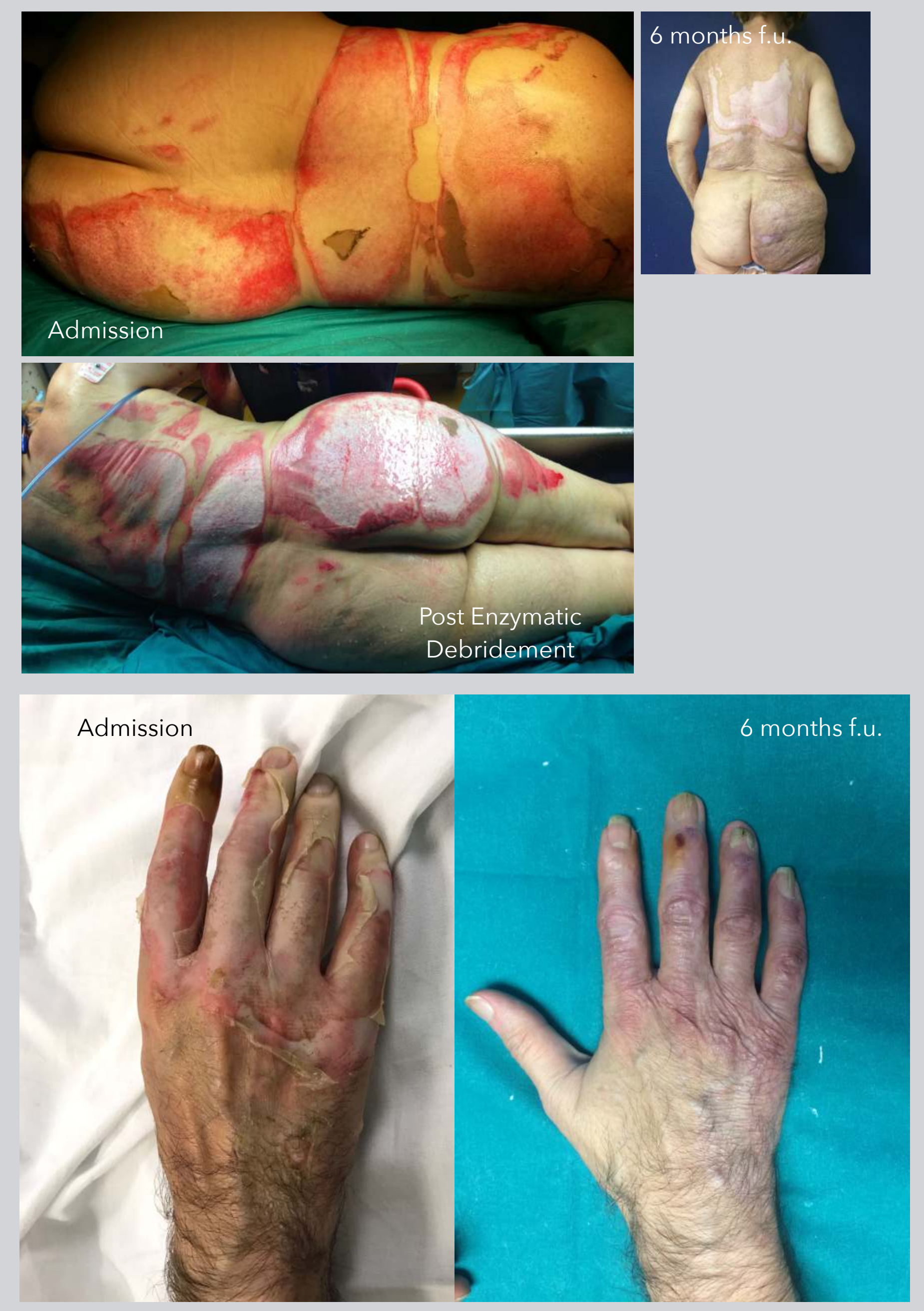

\section{METHODS}

A retrospective study was developed. Patients treated between 2015 to 2017 older than 65 y.o. and with less than $15 \%$ TBSA were collected. The control group was collected from a historical cohort from 2013 and 2014 when enzymatic debridement was not approved in our country. Both groups were homogeneous for TBSA, age, sex and inhalation syndrome. Epidemiological figures, length of stay, number of interventions and mortality was recorded. Statistical evaluation were done using $U$ Mann Whitney and $x^{2}$ tests in SPSS 21.0 Software.

\section{RESULTS}

Eighty patients were enrolled in the study, and divided in two groups: 60 controls and 20 cases. Average TBSA was $6.37 \%$, with a mean age of 78,1 y.o. The mortality ratio was $10 \%$, with same mean values for both groups. The time to complete debridement was $6,77 \pm 7,4$ days in the control group vs $2,15 \pm 1,7$ days in the experimental group. The average number of surgical interventions in the control group was $1,47 \pm 0,74$ and $0,75 \pm 0,71$ in the Nexobrid group. Despite these advantages, the length of stay were not statistically signficant, with $17,43 \pm 13,3$ days in the control group and $19,65 \pm 11,77$ days in the experimental one.

\begin{tabular}{|c|c|c|c|c|}
\hline & & \multicolumn{3}{|l|}{ Tabla 1} \\
\hline & & CONTROL GROUP & ENZYMATIC D. GROUP & $\mathrm{p}$ \\
\hline $\mathrm{n}$ & & 60 & 20 & \\
\hline AGE & & $78.18 \pm 7.9$ & $78.15 \pm 9.13$ & \\
\hline \multicolumn{5}{|l|}{ GENDER } \\
\hline & Female & $23(38 \%)$ & $9(45 \%)$ & \\
\hline & Male & $37(62 \%)$ & $11(55 \%)$ & \\
\hline \multicolumn{5}{|l|}{ MECHANISM } \\
\hline & Scald & $28(44,7 \%)$ & $4(20 \%)$ & \\
\hline & Flame & $23(38,3 \%)$ & $16(80 \%)$ & \\
\hline & Contact & $9(15 \%)$ & $0(0 \%)$ & \\
\hline TBSA \% & & $5.93 \pm 3.75$ & $6.5 \pm 1.10$ & \\
\hline INHALATION INJ. & & $3(5 \%)$ & $1(5 \%)$ & \\
\hline CHARLSON INDEX & & $1.7 \pm 1.6$ & $2.5 \pm 1.99$ & \\
\hline SURGERIES & & $1.47 \pm 0.74$ & $0.75 \pm 0.71$ & 0,031 \\
\hline TIME TO DEBRIDEMENT & & $6.77 \pm 7.44$ & $2.15 \pm 1.69$ & 0,001 \\
\hline LoS (days) & & $17.43 \pm 13.3$ & $19.65 \pm 11.77$ & \\
\hline COLONIZATION & & $7(11,7 \%)$ & $2(10 \%)$ & \\
\hline MORTALITY & & $6(10 \%)$ & $2(10 \%)$ & \\
\hline
\end{tabular}

\section{CONCLUSIONS}

Bromelain based enzymatic debridement allows to reduce the number of surgeries over older patients, reducing the time until complete debridement of burns. No impact over length of stay was demostrated in this study. 